\title{
Localised coastal habitats have distinct underwater sound signatures
}

\author{
C. A. Radford ${ }^{1, *}$, J. A. Stanley ${ }^{1}$, C. T. Tindle ${ }^{2}$, J. C. Montgomery ${ }^{1}$, A. G. Jeffs ${ }^{1}$ \\ ${ }^{1}$ Leigh Marine Laboratory, University of Auckland, PO Box 349, Warkworth 0941, New Zealand \\ ${ }^{2}$ Department of Physics, University of Auckland, PO Box 92019, Auckland 1142, New Zealand
}

\begin{abstract}
There is evidence that ambient underwater sound is used by some pelagic larval reef fishes and decapods as a guide to direct them toward coastal areas. It would be advantageous to these organisms if they were also able to use sound to remotely identify suitable settlement habitats. However, it is unknown whether different coastal habitats produce different sounds that would be capable of providing distinctive cues for larvae. This study identified marked differences in the characteristics of ambient underwater sound at 3 distinct types of coastal habitat: a macroalgal-dominated reef, a sea urchin-dominated reef, and a sandy beach. The sea urchin-dominated reef habitat produced sound that was significantly more intense overall in a biologically important frequency band (800 to $2500 \mathrm{~Hz}$ ), compared with that from macroalgal-dominated reefs and beach habitats. The sound produced by snapping shrimp also exhibited marked differences among habitat types, with the sea urchin-dominated reef having significantly more snaps than the macroalgal-dominated reef or beach habitat. Many of the differences in the sound produced by the 2 reef habitats became more apparent at dusk compared with noon. This study provides evidence that there are significant differences in the spectral and temporal composition of ambient sound associated with different coastal habitat types over relatively short spatial scales. An acoustic cue that conveys both directional and habitat quality information that is transmitted considerable distances offshore would have the potential to be of immense value to the pelagic larval stage of a coastal organism attempting to remotely locate a suitable habitat in which to settle.
\end{abstract}

KEY WORDS: Habitat type - Acoustic cue - Ambient underwater sound - Evening chorus · Larval orientation $\cdot$ Sea urchins $\cdot$ Snapping shrimp

Resale or republication not permitted without written consent of the publisher

\section{INTRODUCTION}

Ambient sea noise is composed of a combination of acoustic sources (Acosta et al. 1997, Cato \& McCauley 2002). Abiotic sources of ambient sea noise in the nearshore environment are mostly due to the effect of the wind and waves that produce noise of frequencies above 150 to $200 \mathrm{~Hz}$. Biotic sound, which covers a very wide range of frequencies, is generated by a variety of marine life involved in reproductive displays, territorial defense, feeding and echolocation (Knudson et al. 1948, Tait 1962, Wenz 1962, Cato 1978, 1992, McCauley \& Cato 2000, Radford et al. 2008a).

Ambient underwater noise varies from place to place (Urick 1983) and the vertical directionality of ambient noise has been extensively studied (e.g. Sotorin \& Hodgkiss 1990 and references therein). However, there is very little literature on the horizontal directionality of ambient noise and Urick (1983) reported 'few or no observations'. The horizontal directionality of noise due to surf and ice movement (Wilson et al. 1985, Yang et al. 1987, Deane 2000) has been described, but no reports of horizontal directionality due to different shore types in coastal waters appear to exist.

Ambient underwater sound is thought to be important in guiding some pelagic larval reef fishes and decapods to settlement habitats on coastal reefs (Tolimieri et al. 2000, 2002, 2004, Jeffs et al. 2003, 2005, Simpson et al. 2004, 2005, 2008a,b, Montgomery et al. 2006, Radford et al. 2007). For example, Simpson et al. 
(2005) showed that the settlement of different species of larval fish on experimental patch reefs were variously affected by the presence and frequency range of underwater sound broadcast from these reefs. While the overall extent to which reef sound influences the natural settlement of reef organisms is unknown, it is possible that spatial variation in ambient underwater sound could contribute to the large amount of spatial variability observed in larval settlement (Doherty 1991, Doherty \& Fowler 1994, Caselle \& Warner 1996). It would be advantageous for larval settlers to be able to remotely detect and respond to differences in underwater sound if the sound reliably represented differences in the coastal settlement habitat at the sound source. Currently, it is unknown whether different habitats that would be encountered over the active swimming distance (i.e. km's) of a larval settler (Stobutzki \& Bellwood 1994, Stobutzki 1998, Dudley et al. 2000) are producing identifiably different sounds due to habitat related differences in the presence and abundance of sound-producing animals, such as snapping shrimp, fishes and sea urchins (Cato 1978, 1992, Radford et al. 2008a,b). While there have been a few previous studies of spatial variation in ambient underwater sound in shallow coastal waters, none to our knowledge have determined whether coastal habitats on the spatial scale encountered by a larval settler are producing distinct sound profiles.

The spatial extent to which larval settlers can use ambient underwater sound as an orientation cue is still controversial (e.g. Mann et al. 2007). Establishing a basis of the acoustic environment within which larval fish and decapods live is a prerequisite to defining the effective range of sound for orientation. Therefore, the aim of the present study was to describe differences in the gross character (temporal variation, spectral composition and spectrum level) of reef sound emanating from 3 types of habitat on a temperate coast (macroalgal-dominated rocky reef, sea urchin barren rocky reef and sandy beach) that were all located only a few kilometres apart. The results presented are selected from a comprehensive 1 yr study of underwater sound along about $50 \mathrm{~km}$ of varied coastline to investigate variations with shore type, season and time of day (Radford 2007).

Ambient underwater noise was defined by Urick (1983) as 'the residue noise background in the absence of individual identifiable sources that may be considered the natural noise environment of the hydrophone'. For the purposes of this study the main source of the sound energy is known to be sea urchins and snapping shrimp (Radford et al. 2008a,b). Even though the sound forms part of the ambient 'noise' it becomes the signal of interest when we consider its possible use for orientation and guidance and, hence, with appro- priate qualification can be referred to as reef noise or reef sound.

\section{MATERIALS AND METHODS}

Radford et al. (2008b) showed that there was an intensity maximum in sounds produced by sea urchin and snapping shrimp during the new moon and a minimum during the full moon, with no difference between the 2 quarter moons. There was also a minimum (noon) and maximum (dusk) in sea urchin and shrimp sound activity during a $24 \mathrm{~h}$ period. Therefore, to assess spatial variation in reef sound recordings of ambient underwater noise were taken during October 2008 on the first and last quarter moon phases at 6 sites around the coast near Leigh in northeastern New Zealand (Fig. 1). There were 3 habitat types with 2 different sites for each habitat: macroalgal-dominated rocky reef (M1, M2), sea urchin-dominated rocky reef (U1, U2), open sandy beach, Pakiri Beach (B1, B2). These site selections were based on a previously created habitat map. Recordings were made using a floating hydrophone system to reduce extraneous noise. The system consisted of a sealed barrel that contained a Sound Devices 722 solid state recorder $(48 \mathrm{kHz}, 24 \mathrm{bit})$, which was connected to a calibrated HTI-96-MIN wideband omnidirectional hydrophone (High Tech). The hydrophone had a flat frequency response curve over the range of $10 \mathrm{~Hz}$ to $24 \mathrm{kHz}$ and was weighted vertically to $10 \mathrm{~m}$ water depth from the outside of the floating barrel. Recordings of $5 \mathrm{~min}$ duration were made during 12:00 to 13:00 h (noon) and 17:00 to $18: 00 \mathrm{~h}$ (dusk) at 10 to $20 \mathrm{~m}$ from the reef edge or $100 \mathrm{~m}$ from the shoreline of the sandy beach, which corresponded to $20 \mathrm{~m}$ water depth for the reef sites and $15 \mathrm{~m}$ for the beach sites.

The digital recordings were transferred to a personal computer and analysed using MATLAB software with codes specifically written for these recordings. Wind speed was recorded simultaneously every hour at the nearby climate station at the University of Auckland's Leigh Marine Laboratory.

Data analysis. No extraneous anthropogenic sources of noise, such as ships, power boats or nearby coastal activities were present in the recordings. All recordings were conducted in calm or near calm conditions (wind speed $<5$ knots [ 9 $\left.\mathrm{km} \mathrm{h}^{-1}\right]$ and wave height $<0.25 \mathrm{~m}$ ). However, to ensure that variability in wind speeds did not exert an influence on the ambient underwater sound recordings, wind speeds were compared among all sites using ANOVA.

Each 5 min recording was examined for uniformity and acoustic power spectra were generated by analysis of 5 randomly selected 10 s samples. Data was highpass filtered to $100 \mathrm{~Hz}$ to remove any effect of surface 


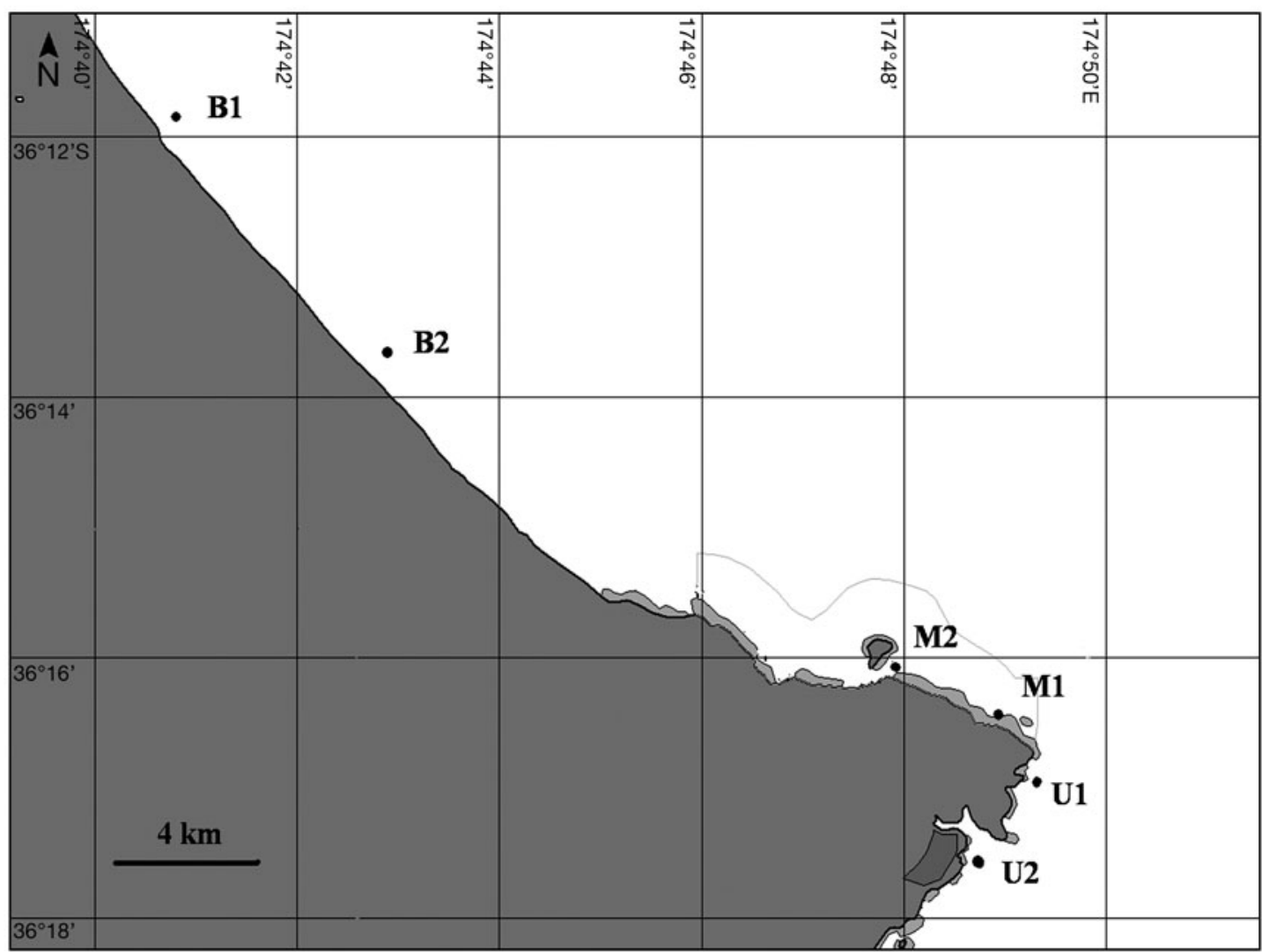

Fig. 1. Study sites off the northeastern coast of the North Island of New Zealand. U1: Rusty Ladder; U2: Nordic Reef; M1: One Spot Reef; M2: Waterfall Reef; B1 and B2: Pakiri Beach. Dark grey: land; light grey: intertidal; white: sea

waves and any $50 \mathrm{~Hz}$ interference. For each of the 5 randomly selected subsamples the total sound intensity $\left(P_{\mathrm{rms}}{ }^{2}\right)$ was calculated. The subsamples were then band-pass filtered into 4 frequency bands 100 to $800 \mathrm{~Hz}, 800$ to $2500 \mathrm{~Hz}$ (sea urchin feeding frequency; Radford et al. 2008a) 2500 to $20000 \mathrm{~Hz}$ (dominant snapping shrimp frequency; $\mathrm{Au} \&$ Banks 1998) and 20000 to $24000 \mathrm{~Hz}$, and the overall proportion of total sound intensity in each frequency band was calculated. For each period (noon or dusk) the proportion of total sound intensity was analysed using a general linear mixed model, with Frequency Band, Habitat and Time (noon and dusk) as fixed factors. Habitat and Frequency Band were also nested within the random effect of Site. Significant differences between individual pairs of means were determined using Tukey's tests.

For each recording, the 5 randomly selected $10 \mathrm{~s}$ subsamples were taken and the number of snaps produced by snapping shrimp was estimated by setting a threshold level on the raw data and any transient spike that was $<0.2 \mathrm{~s}$ duration and above a preset threshold level was counted as a snap by a shrimp. Preliminary manual analyses confirmed that this automated method provided a reliable count of snapping shrimp snaps. The mean number of snaps for each recording site was compared with a general linear mixed model, which enabled comparisons to be made among Time (noon and dusk) and Habitat (fixed effects). Time and Habitat were also nested within Site (random effect) (Littell et al. 1996, McCullagh \& Searle 2001). Significant differences between individual pairs of means were determined using Tukey's tests. All data were analysed using SAS and presented as the statistical mean $+\mathrm{SE}$ of the mean.

\section{RESULTS}

Wind speeds were similar among the times for which the underwater noise recordings were taken for each of the sites $\left(F_{5,160}=1.0, \mathrm{p}=0.55\right)$; therefore, wind was ruled out as the cause of any differences in the recorded ambient noise. Sea swell conditions were also not considered to have affected the recordings because all recordings were taken in conditions of $<0.25 \mathrm{~m}$ swell (Climate Station, Leigh Marine Laboratory unpubl. data). 


\section{Spectra}

The spectra for the 6 sites are shown in Fig. 2. There is a clear similarity between M1 and M2 and between B1 and B2. There is less similarity between $\mathrm{U} 1$ and $\mathrm{U} 2$ but both show an increase at dusk in the 800 to $2500 \mathrm{~Hz}$ band. In general the spectra divided naturally into the broad bands mentioned earlier. The 100 to $800 \mathrm{~Hz}$ band is due to small waves, some fish species and low frequency noise from distant shipping and offshore storms. The 800 to $2500 \mathrm{~Hz}$ band is dominated by sea urchins with a peak around 1000 to $1200 \mathrm{~Hz}$, and the 2.5 to $20 \mathrm{kHz}$ band is dominated by snapping shrimp with a broad peak at $5 \mathrm{kHz}$. Overall, sea urchin noise shows a significant increase in spectrum level between noon and dusk and snapping shrimp noise shows a smaller increase. Spectra B1 and B2 show low levels of sea urchin and snapping shrimp noise at dusk, which is probably due to sound from distant reefs. The higher
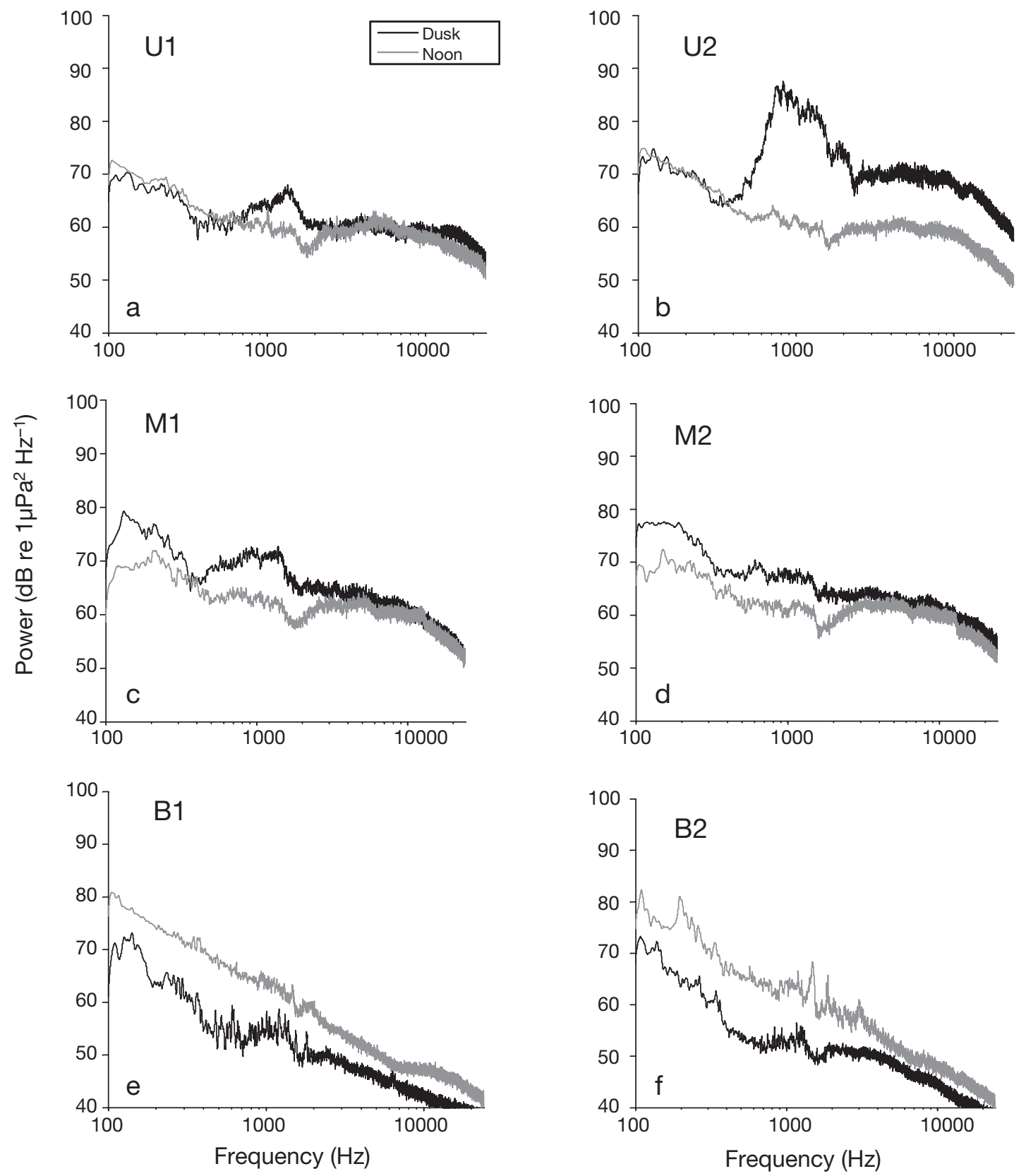

Fig. 2. Noon and dusk spectra: (a) U1: Rusty Ladder; (b) U2: Nordic Reef; (c) M1: One Spot Reef; (d) M2: Waterfall Reef; (e) B1: Pakiri Beach 1; (f) B2: Pakiri Beach 2 
overall levels at noon are due to small waves at the shore from daytime sea breezes.

The spectra in Fig. 2 for different habitats are different in their overall appearance suggesting that acoustic characteristics vary over relatively small spatial scales, and within habitats, between noon and dusk. In general, all the reef sites (U1, U2, M1 and M2) had higher power level in the frequency band 2500 to $20000 \mathrm{~Hz}$, whereas the 2 beach sites (B1 and B2) did not. The 2 sites at sea urchin-dominated habitat had an additional large (10 to $20 \mathrm{~dB}$ ) increase in power between 800 and $2500 \mathrm{~Hz}$ at dusk when compared
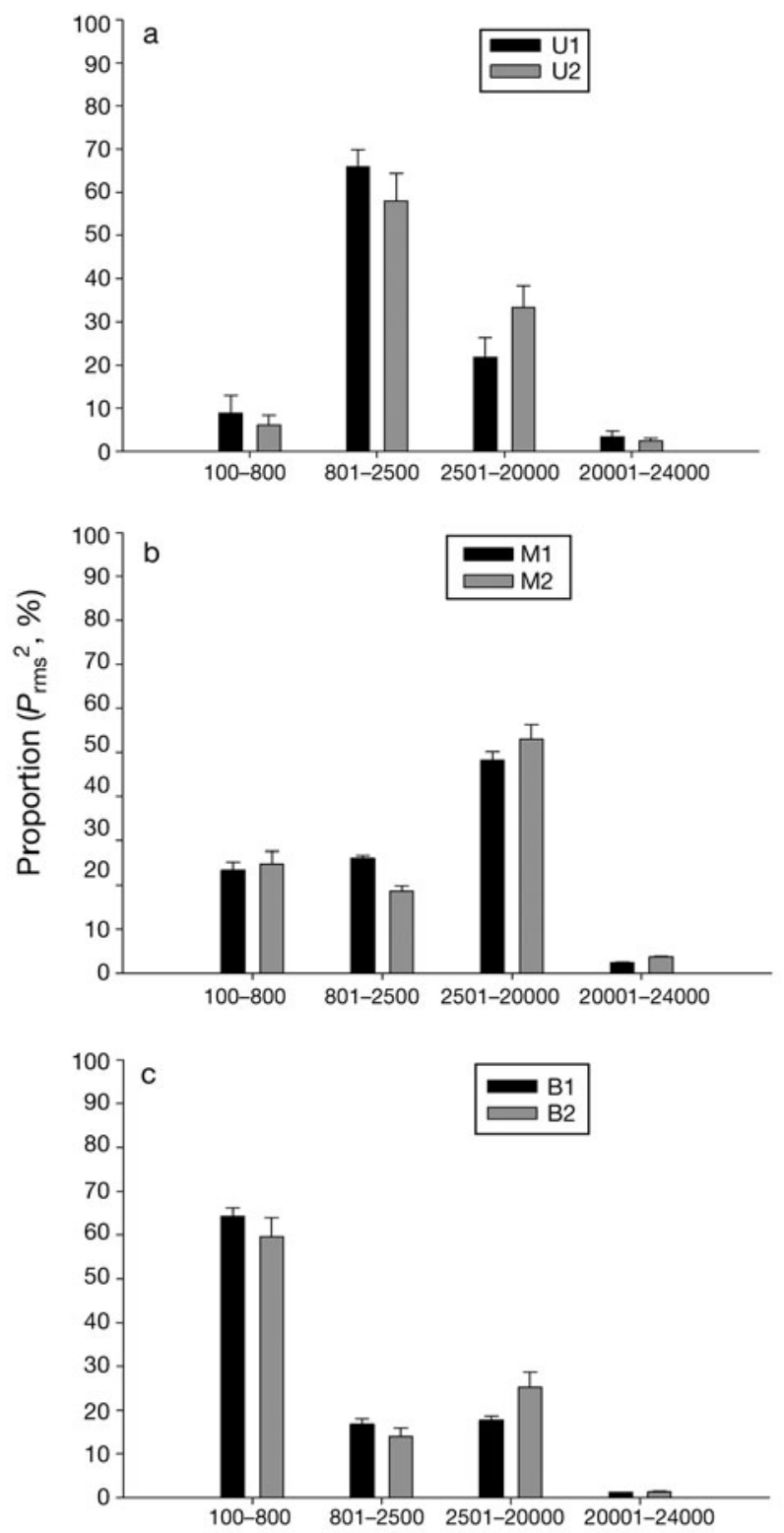

with noon, whereas the macroalgal-dominated habitat had smaller increases of about $5 \mathrm{~dB}$. The 2 sites at the sandy beach habitat had higher power levels in the lower frequencies (100 to $300 \mathrm{~Hz}$ ) compared with all of the 4 sites at reef habitats.

\section{Proportion of total sound intensity}

At noon the proportion of sound intensity in the different frequency bands (Fig. 3d-f) was significantly different for Frequency $\left(F_{3,9}=74.20, \mathrm{p}<0.0001\right)$ and
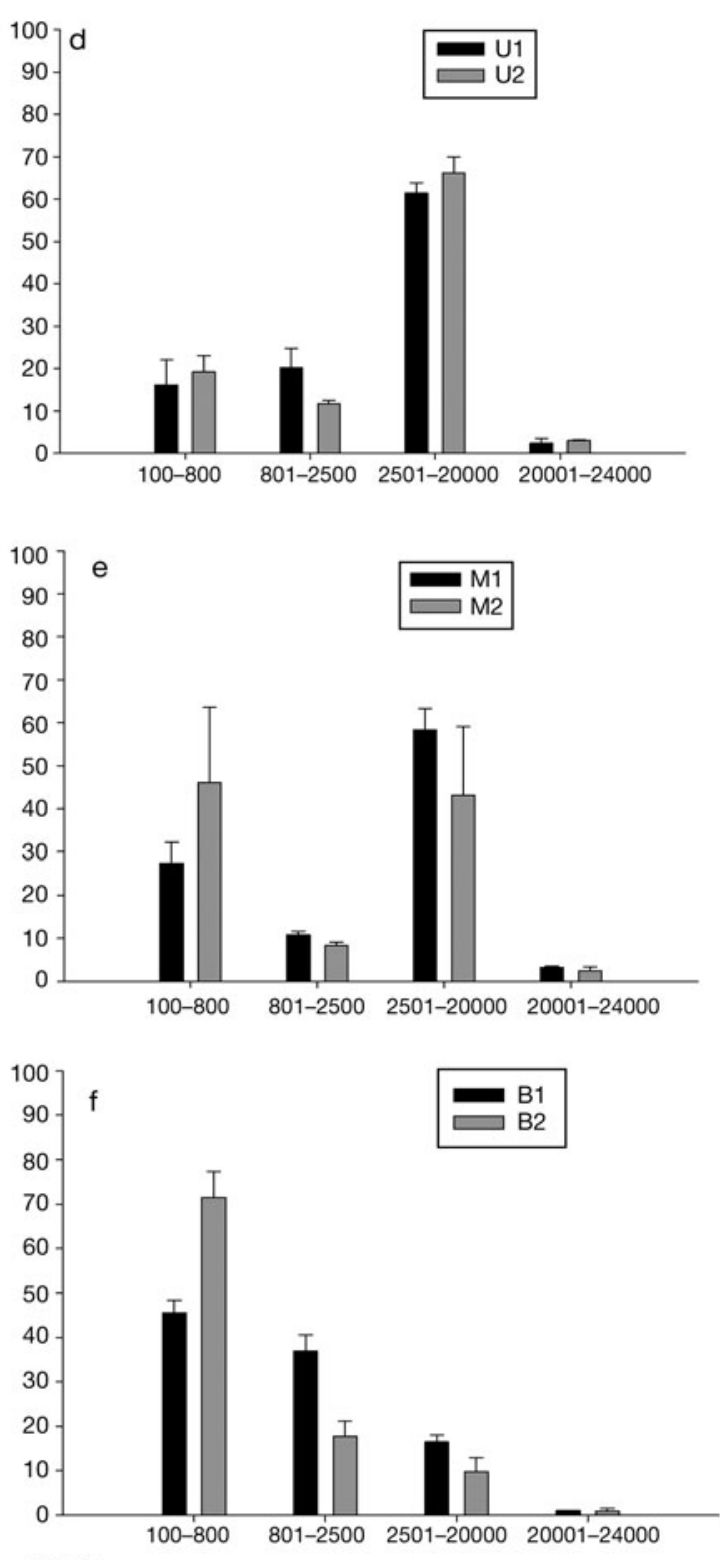

Frequency band $(\mathrm{Hz})$

Fig. 3. Proportion of total noise intensity $\left(P_{\mathrm{rms}}{ }^{2}\right.$, mean $\left.+\mathrm{SE}\right)$ occurring in the biologically dominant frequency bands at (a-c) dusk or $(d-f)$ noon 
the interaction Habitat $\times$ Frequency $\left(F_{6,9}=7.58, \mathrm{p}<\right.$ $0.01)$, but was similar between Habitat $\left(F_{2,3}=0.19, \mathrm{p}=\right.$ 0.83 ). All sites were similar in the frequency band 800 to $2500 \mathrm{~Hz}$, while at dusk (Fig. 3a-c) the sea urchin habitats had the greatest proportion of total sound intensity. At noon the macroalgal and sea urchin habitats were similar in the frequency band 2500 to 20000 $\mathrm{Hz}$, but these were significantly greater than for the beach habitat. For all other frequency bands the habitats were similar.

At dusk the proportion of total sound intensity in different frequency bands showed significant differences for Site (Habitat) $(F=28.15, \mathrm{p}<0.01)$, Site (Habitat $\times$ Frequency) $(F=38.96, \mathrm{p}<0.05)$, Habitat $\left(F_{2,3}=3.44, \mathrm{p}\right.$ $<0.05)$, Frequency $\left(F_{3,9}=197.97, \mathrm{p}<0.001\right)$ and the interaction Habitat $\times$ Frequency $\left(F_{6,9}=32.52, \mathrm{p}<\right.$ 0.001 ). The sea urchin-dominated habitat had a significantly higher proportion of total sound intensity (range, 55 to $65 \%$ ) in the frequency band 800 to $2500 \mathrm{~Hz}$ at dusk compared with the other 2 habitat types, macroalgal reef (range, 15 to $25 \%$ ) and sandy beach (range, 15 to $20 \%$ ). However, the macroalgal reef sites had a significantly higher proportion of total sound intensity in the frequency bands 2500 to $20000 \mathrm{~Hz}$ (range, 45 to $55 \%$ ) than did the sea urchin reef (range, 20 to $30 \%$ ) and sandy beach habitat (range, 15 to $25 \%$ ) at dusk. At dusk the sandy beach habitat had the highest proportion (range, 58 to $63 \%$ ) of total sound intensity in the frequency 100 to $800 \mathrm{~Hz}$ band $(\mathrm{p}<0.05)$ and the urchin habitat had the lowest proportion (range, 8 to $10 \%)(\mathrm{p}<0.05)$. All of the habitats had a similar proportion of total sound intensity in the 20000 to $24000 \mathrm{~Hz}$ band ( $p>0.05$ ) at dusk.

Overall, the sea urchin-dominated reefs (U) at dusk had a significantly greater proportion of sound intensity in the frequency band 800 to $2500 \mathrm{~Hz}$ compared with those at noon $(\mathrm{p}<0.01)$. In contrast, the proportion of sound intensity in the frequency band 2500 to $20000 \mathrm{~Hz}$ for the sea urchin-dominated reefs was lower at dusk than at noon $(\mathrm{p}<0.01)$. The macroalgaedominated reefs $(\mathrm{M})$ had a significant rise in the proportion of sound intensity in the 800 to $2500 \mathrm{~Hz}$ frequency band at dusk compared with that at noon ( $p<$ 0.05 ); whereas, the sandy beach habitats (B) were similar at dusk and noon.

\section{Snapping shrimp}

The number of snaps produced by snapping shrimp (Fig. 4) exhibited significant differences for Site (Habitat) $(F=8713.2, \mathrm{p}<0.05)$, Habitat $\left(F_{2,3}=9.01, \mathrm{p}<0.05\right)$, Time $\left(F_{1,3}=43.46, \mathrm{p}<0.01\right)$ and the interaction Time $\times$ Habitat $\left(F_{2,3}=9.19, \mathrm{p}<0.05\right)$. Overall, the Nordic Reef site (U2) had significantly more snaps produced by

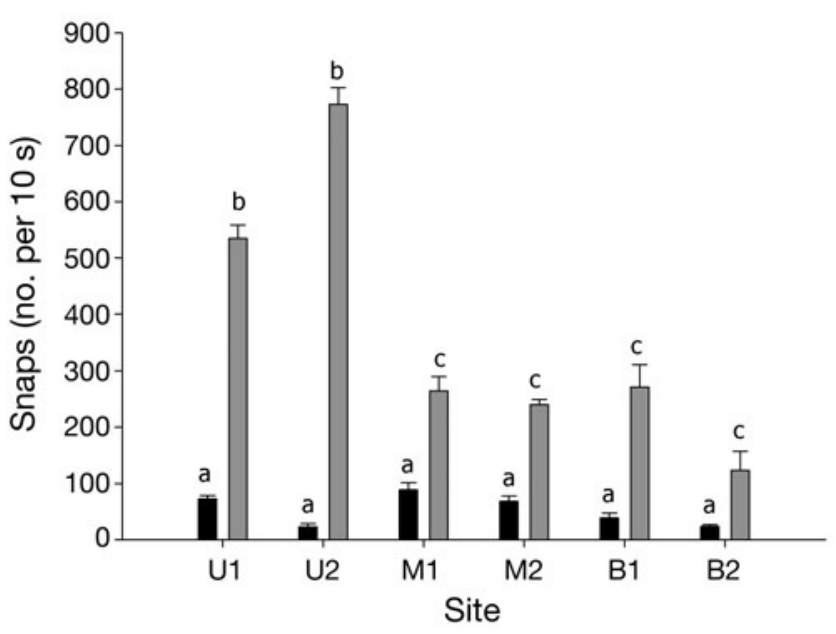

Fig. 4. Alpheus spp. and Syalpheus spp. Mean number (+SE) of snaps of snapping shrimp in $10 \mathrm{~s}$ for the 6 study sites at noon (grey) and dusk (black). See Fig. 1 for site locations

snapping shrimp than any other site, while Pakiri Beach 2 (B2) had the least. Both sea urchin-dominated reef sites (U1 and U2) had similar numbers of snaps, but had significantly more than the 2 macroalgal reef sites (M1 and M2). Significantly more snaps were recorded at the sea urchin habitat sites during dusk (ranging from 550 to 750 snaps per 10 s) than at the macroalgae habitat sites ( 240 to 280 snaps per $10 \mathrm{~s}$ ) and the beach habitat sites (120 to 260 snaps per $10 \mathrm{~s}$ ). There were significantly more snaps produced by snapping shrimp during dusk than at noon for every site; however, the number of snaps produced at noon was similar among all the sites (range, 20 to 100 snaps 10 per $10 \mathrm{~s})$.

\section{DISCUSSION}

The aim of the present study was to describe gross differences in the spectral composition and level of the ambient noise emanating from 3 distinct types of habitat on a temperate coast (macroalgal-dominated reef, sea urchin-dominated reef, and sandy beach) all within relatively close proximity (a few $\mathrm{km}$ apart). Analyses of representative samples of underwater noise revealed there were marked differences between the habitat types, especially in specific frequency bands. In particular, the frequency band associated with sea urchin feeding (800 to $2500 \mathrm{~Hz}$ ) was significantly more intense at the sea urchin-dominated reef habitat sites (U1 and U2) than at the macroalgaldominated reef and the sandy beach habitats. This is confirmed by the proportion of total sound intensity in the frequency band 800 to $2500 \mathrm{~Hz}$ being significantly greater at the sea urchin habitat sites than at either the 
macroalgal reef or sandy beach habitat sites. In contrast, the sounds recorded at sites of the same gross habitat type (i.e. sandy beach, sea urchin barren reef, macroalgal reef) were similar in terms of their spectral composition and temporal changes in their spectra.

To our knowledge this is the first study to observe marked differences in underwater noise levels over such small geographical scales (a few km) and associated with localised differences in habitat type. The greatest differences in the acoustic output from 3 distinctive coastal habitats were observed among the recordings taken at dusk. This suggests that underwater sound recordings should be conducted at dusk to determine differences between habitat types. The 800 to $2500 \mathrm{~Hz}$ frequency band caused most of the variation among the habitats at dusk, with the likely cause of this associated with the feeding behaviour of grazing sea urchins, which resonate at frequencies between 800 to $2500 \mathrm{~Hz}$ depending on their size (Radford et al. 2008a). The presence of large numbers of sea urchins is an important characteristic of coastal reefs in New Zealand and their grazing activity is of major importance in maintaining the barren reef habitat (Shears \& Babcock 2002, 2003).

Another source of variation within the data was due to one of the most ubiquitous sound-producing animals in marine temperate waters, the snapping shrimp (Fish 1964, Cato 1992, Au \& Banks 1998, Cato \& McCauley 2002). Snapping shrimp dwell in a range of habitats from shallow bays and estuaries to rocky and coral reefs (Au \& Banks 1998). The total output of sound by snapping shrimp is influenced by the size of the shrimp bed and time of day (Fish 1964, Radford et al. 2008b). Assuming that the number of snaps estimated from sound recordings broadly indicates the number of snapping shrimp, i.e. Alpheus spp. and Syalpheus spp., present on and around the reef, the sea urchindominated reef type had significantly more shrimp than the macroalgal reef habitat. This suggests that habitat type is important in determining the abundance of resident snapping shrimp. In contrast, previous studies have shown that macroalgal habitats are more diverse and complex than sea urchin barren habitats (Simenstad et al. 1978, Behrens \& Lafferty 2004, Graham 2004, Tuya et al. 2006). Watanabe et al. (2002) used the numbers of snaps produced by snapping shrimp as an environmental monitoring tool and showed that the number of snaps produced in an unpolluted habitat was significantly greater than at a polluted site. Therefore, the results of the present research also highlight the potential use of passive acoustics as a tool for monitoring habitat quality, remotely surveying habitat type and determining the abundance of some sound-producing organisms, such as snapping shrimp.
This study shows that different types of coastal habitat found over a relatively small spatial scale $(\mathrm{km} / \mathrm{s})$ have marked differences in their spectral frequency and level composition of the ambient underwater sound they produce. The 2 types of reef habitat examined in this study both produced sound of sufficient intensity in frequency ranges that were likely to be transmitted some distance beyond the habitat (Radford et al. 2005). The sound output from both types of reef habitat was significantly higher at dusk than at noon. Dusk is also the time when the nocturnal settling stages of many coastal reef fishes and crustaceans become active in the water column. A number of studies have now produced evidence that the pelagic settling stages of some reef-dwelling fishes and crustaceans are capable of orienting toward ambient underwater sound produced by reefs (Tolimieri et al. 2000, 2002, 2004, Jeffs et al. 2003, 2005, Simpson et al. 2004, 2005, 2008a, Montgomery et al. 2006, Radford et al. 2007). This ability, combined with strong swimming capabilities identified in many of these settling stages (Stobutzki \& Bellwood 1994, 1997, Shanks 1995, Leis \& Carson-Ewart 1997, 1999, Stobutzki 1997, 1998, Jeffs \& Holland 2000, Jeffs et al. 2005, Fisher et al. 2005), would theoretically provide increased capacity for settlers to reach suitable settlement habitat.

Acoustic cues that convey directional as well as habitat quality information would potentially be of immense value to the pelagic larval stage of a reef organism attempting to remotely locate a suitable habitat in which to settle. Three studies provide some limited support for this proposition. Divers in the field observed a clear difference in the swimming speed and directional movements of the settlement stage of the reef fish Chromis atripectoralis in the vicinity of underwater speakers broadcasting either natural reef sound or artificial pure tones, suggesting that settlingstage fishes have the ability to discriminate and respond to different underwater sounds (Leis et al. 2002). Simpson et al. (2005) showed that the settlement of different species of settlement-stage fish on experimental patch reefs were affected by differences in the frequency range of underwater sound broadcast from the reefs. The broadcast sound consisted of recordings of natural reef sound filtered into high frequency $(>570$ $\mathrm{Hz})$ or low frequency $(<570 \mathrm{~Hz})$ components. The researchers found that pomacentrid fish species responded preferentially to the high frequency treatment, while other fishes, such as apogonids, showed no preference between the 2 different sound treatments. Simpson et al. (2008b) conducted a similar experiment by broadcasting high frequency (570 to $2000 \mathrm{~Hz})$ and low frequency $(<570 \mathrm{~Hz})$ components of natural reef sound in conjunction with light traps, which are widely used for catching settlement-stage 
reef fish. Of the 7 fish families represented in catches of $>10$ individuals, 4 were caught in significantly greater numbers in the high-frequency traps than in either the low-frequency or the silent traps (Pomacentridae, Apogonidae, Lethrinidae and Gobiidae). Only the family Siganidae showed no preference between any of the sound treatments.

Overall, these results suggest that settlement-stage fish are able to discriminate differences in acoustic cues, which may relate to possible differences in habitat. This ability appears to be retained after settlement as juvenile and adult fish. Simpson et al. (2008a) found that the highest diversity of both adult and juvenile reef fish was found in experimental patch reefs broadcasting the low frequency $(<570 \mathrm{~Hz})$ component of natural reef sound compared with those broadcasting high frequency component $(>570 \mathrm{~Hz})$. In addition, the adults from 2 fish families (Gobiidae and Blenniidae) preferred to relocate to patch reefs broadcasting the low frequency sound, while juvenile Acanthuridae preferred the patch reefs with higher frequency sound. These previous findings, together with our results, indicate that differences in underwater sound emanating from different types of habitat may play a significant role in settlement processes as well as in the orientation of juveniles and adults of some species. The results reported here show that statistically significant differences in sound occur over relatively short distances and could provide a basis for habitat selection by settling fish.

Acknowledgements. We thank N. Tolimieri for statistical advice and J. Evans and M. Birch for assistance with the construction of the remote hydrophone recorders. We are grateful to an anonymous referee for suggestions to improve this manuscript. This research was supported by the Marsden Fund of the Royal Society of New Zealand.

\section{LITERATURE CITED}

Acosta CA, Mathews TR, Butler MJ IV (1997) Temporal patterns and transport processes in the recruitment of spiny lobster (Panulirus argus) postlarvae to south Florida. Mar Biol 129:79-85

Au WL, Banks K (1998) The acoustics of the snapping shrimp Synalpheus parneomeris in Kaneohe Bay. J Acoust Soc Am 103:41-44

Behrens MD, Lafferty KD (2004) Effects of marine reserves and urchin disease on southern Californian rocky reef communities. Mar Ecol Prog Ser 279:129-139

Caselle JE, Warner RR (1996) Variability in recruitment of coral reef fishes: the importance of habitat at two spatial scales. Ecology 77:2488-2504

Cato DH (1978) Marine biological choruses observed in tropical waters near Australia. J Acoust Soc Am 64:736-743

Cato DH (1992) The biological contribution to the ambient noise in waters near Australia. Acoust Aust 20:76-80

Cato DH, McCauley RD (2002) Australian research in ambient sea noise. Acoust Aust 30:13-20
Deane GB (2000) A model for the horizontal directionality of breaking wave noise in the surf zone. J Acoust Soc Am 107:177-192

Doherty PJ (1991) Spatial and temporal patterns in recruitment. In: Sale PF (ed) The ecology of fishes on coral reefs. Academic Press, San Diego, CA, p 261-293

> Doherty P, Fowler T (1994) An empirical test of recruitment limitation in a coral reef fish. Science 263:935-939

> Dudley B, Tolimieri N, Montgomery JC (2000) Swimming ability of the larvae of some reef fishes from New Zealand waters. Mar Freshw Res 51:783-787

Fish MP (1964) Biological sources of sustained ambient sea noise. In: Tavolga WN (ed) Marine bio-acoustics. Pergamon Press, New York, NY, p 175-194

Fisher R, Leis JM, Clake DL, Wilson SK (2005) Critical swimming speeds of late-stage coral reef fish larvae: variation within species, among species and between locations. Mar Biol 148:1425-1434

Graham MH (2004) Effects of local deforestation on the diversity and structure of southern California giant kelp forest food webs. Ecosystems 7:341-357

Jeffs A, Holland RC (2000) Swimming behaviour of the puerulus of the spiny lobster, Jasus edwardsii (Hutton, 1875) (Decapoda: Palnuridae). Crustaceana 73:847-856

Jeffs A, Tolimieri N, Montgomery J (2003) Crabs on cue for the coast: the use of underwater sound for orientation by pelagic crab stages. Mar Freshw Res 54:841-845

Jeffs A, Montgomery JC, Tindle C (2005) How do spiny lobster post-larvae find the coast? NZ J Mar Freshw Res 39:605-617

Knudson VO, Alford RS, Emling JW (1948) Underwater ambient noise. J Mar Res 7:410-429

Leis JM, Carson-Ewart BM (1997) In situ swimming speeds of late pelagic larvae of some Indo-Pacific coral reef fishes. Mar Ecol Prog Ser 159:165-174

> Leis JM, Carson-Ewart BM (1999) In situ swimming and settlement behaviour of larvae of an Indo-Pacific reef fish, the coral trout Plectropomus leopardus (Pisces: Serranidae). Mar Biol 134:51-64

Leis JM, Carson-Ewart BM, Cato DH (2002) Sound detection in situ by the larvae of a coral-reef damselfish (Pomacentridae). Mar Ecol Prog Ser 232:259-268

Littell RC, Miliken GA, Stroup WW, Wolfinger RD (1996) SAS system for mixed models. SAS, Cary, NC

> Mann DA, Casper BM, Boyle KS, Tricas TC (2007) On the attraction of larval fishes to reef sounds. Mar Ecol Prog Ser 338:307-310

> McCauley RD, Cato DH (2000) Patterns of fish calling in a nearshore environment in the Great Barrier Reef. Philos Trans R Soc Lond B Biol Sci 355:1289-1293

McCullagh CE, Searle RS (2001) Generalized, linear, and mixed models. John Wiley \& Sons, New York, NY

Montgomery JC, Jeffs A, Simpson SD, Meekan M, Tindle C (2006) Sound as an orientation cue for the pelagic larvae of reef fish and decapod crustaceans. Adv Mar Biol 51: 143-199

Radford CA (2007) Ambient underwater sound: understanding its origins, variations and biological role. $\mathrm{PhD}$ thesis, University of Auckland

Radford CA, Jeffs AG, Tindle CT, Cole RG, Montgomery JC (2005) Bubbled waters: the noise produced by underwater breathing apparatus. Mar Freshw Behav Physiol 38: 259-268

Radford CA, Jeffs AG, Montgomery JC (2007) Directional swimming behaviour by five species of crab postlarvae in response to reef sound. Bull Mar Sci 80:369-378

Radford CA, Jeffs AG, Tindle CT, Montgomery JC (2008a) 
Resonating sea urchin skeletons create coastal choruses. Mar Ecol Prog Ser 362:37-43

Radford CA, Jeffs AG, Tindle CT, Montgomery JC (2008b) Temporal patterns in ambient underwater noise at a shallow temperate reef. Oecologia 156:921-929

Shanks A (1995) Orientated swimming by megalopae of several eastern North Pacific crab species and its potential role in their onshore migration. J Exp Mar Biol Ecol 186: $1-16$

Shears NT, Babcock RC (2002) Marine reserves demonstrate top down control of community structure on temperate reefs. Oecologia 132:131-142

Shears NT, Babcock RC (2003) Continuing trophic cascade effects after 25 years of no-take marine reserve protection. Mar Ecol Prog Ser 246:1-16

Simenstad CA, Estes JA, Kenyon KW (1978) Aleuts, sea otters, and alternate stable-state communities. Science 200:403-411

Simpson SD, Meekan MG, McCauley RD (2004) Attraction of settlement stage coral reef fishes to reef noise. Mar Ecol Prog Ser 276:263-268

Simpson SD, Meekan MG, Montgomery JC, McCauley RD, Jeffs A (2005) Homeward sound. Science 308:221

Simpson SD, Jeffs A, Montgomery JC, McCauley RD, Meekan MD (2008a) Nocturnal relocation of adult and juvenile coral reef fishes in response to reef noise. Coral Reefs 27:97-104

Simpson SD, Meekan MG, Jeffs AG, Montgomery JC, McCauley RD (2008b) Settlement-stage coral reef fishes prefer the higher frequency invertebrate-generated audible component of reef noise. Anim Behav 75:1861-1868

Sotorin BJ, Hodgkiss WS (1990) Fine-scale measurements of the vertical ambient noise field. J Acoust Soc Am 87: 2053-2063

Stobutzki IC (1997) Energetic cost of sustained swimming in the late pelagic stages of reef fishes. Mar Ecol Prog Ser 152:249-259

Stobutzki IC (1998) Interspecific variation in sustained swim-

Editorial responsibility: Otto Kinne,

Oldendorf/Luhe, Germany ming ability of late stage reef fish from two families (Pomacentridae and Chaetodontidae). Coral Reefs 17: 111-119

Stobutzki IC, Bellwood DR (1994) An analysis of the sustained swimming abilities of presettlement and postsettlement coral-reef fishes. J Exp Mar Biol Ecol 175:275-286

Stobutzki IC, Bellwood DR (1997) Sustained swimming in the late stage of pelagic reef fishes. Mar Ecol Prog Ser 149: $35-41$

Tait RI (1962) The evening chorus: a biological noise investigation. Naval Research Laboratory Report No. 26. HMNZ Dockyard, Auckland

Tolimieri N, Jeffs A, Montgomery JC (2000) Ambient sound as a cue for navigation by the pelagic larvae of reef fishes. Mar Ecol Prog Ser 207:219-224

Tolimieri N, Haine O, Montgomery JC, Jeffs A (2002) Ambient sound as a navigational cue for larval reef fish. Bioacoustics 12:214-217

Tolimieri N, Haine O, Jeffs A, McCauley R, Montgomery JC (2004) Directional orientation of pomacentrid larvae to ambient reef sounds. Coral Reefs 23:184-191

Tuya F, Hernandez JC, Clemente S (2006) Is there a link between the type of habitat and the patterns of abundance of holothurians in shallow rocky reefs? Hydrobiologia 571: 191-199

Urick RJ (1983) Principles of underwater sound, McGrawHill, New York, NY

Watanabe M, Sekine M, Hamada E, Ukita M, Imai T (2002) Monitoring of shallow sea environment by using snapping shrimps. Water Sci Technol 46:419-424

Wenz GM (1962) Acoustic ambient noise in the ocean: spectra and sources. J Acoust Soc Am 34:1936-1957

Wilson OB Jr, Wolf SN, Ingenito F (1985) Measurements of acoustic ambient noise in shallow water due to breaking surf. J Acoust Soc Am 78:190-195

Yang TC, Giellis GR, Votaw CW, Diachok OI (1987) Acoustic properties of ice edge noise in the Greenland Sea. J Acoust Soc Am 82:1034-1038

Submitted: April 1, 2009; Accepted: December 7, 2009

Proofs received from author(s): February 11, 2010 